\title{
$\mathrm{Zr}-\mathrm{Sn}-\mathrm{Fe}-\mathrm{Cr}$ 및 $\mathrm{Zr}-\mathrm{Nb}-\mathrm{Sn}-\mathrm{Fe}$ 합금 피복관의 기계적 특성 및 $\mathrm{Creep}$ 거동
}

\author{
이상용** · 고산 · 최영철 · 김규태* · 최재하** · 홍순익 ${ }^{\dagger}$ \\ 충남대학교 나노소재공학과 \\ *한전원자력연료(주), **충북대학교 재료공학과
}

\section{Mechanical Properties and Creep Behaviors of Zr-Sn-Fe-Cr and Zr-Nb-Sn-Fe Alloy Cladding Tubes}

\author{
Sang-Yong Lee**, San Ko, Young-Chul Choi, Kyu-Tae Kim*, Jae-Ha Choi**, Sun-Ig Hong ${ }^{\dagger}$ \\ Department of Nano-materials Engineering, Chungnam National University, Daejeon, Korea \\ *Korea Atomic Energy Research Institute, Daejeon, Korea \\ **Department of Materials Engineering Chungbuk National University, Cheongju, Korea
}

(2008년 5월 20일 접수 : 2008년 6월 17일 채택)

\begin{abstract}
Since the 1990s, the second generation of Zirconium alloys containing main alloy compositions of $\mathrm{Nb}$, $\mathrm{Sn}$ and $\mathrm{Fe}$ have been used as a replacement of Zircaloy-4 (Zr-Sn-Fe-Cr), a first-generation Zirconium alloy, to meet severe and rigorous reactor operating conditions characterized by high-burn-up, high-power and high-pH operations. In this study, the mechanical properties and creep behaviors of $\mathrm{Zr}-\mathrm{Sn}-\mathrm{Fe}-\mathrm{Cr}$ and $\mathrm{Zr}-\mathrm{Nb}-\mathrm{Sn}-\mathrm{Fe}$ alloys were investigated in a temperature range of $450 \sim 500^{\circ} \mathrm{C}$ and in a stress range of $80 \sim 150 \mathrm{MPa}$. The mechanical testing results indicate that the yield and tensile strengths of the $\mathrm{Zr}-\mathrm{Nb}-\mathrm{Sn}-\mathrm{Fe}$ alloy are slightly higher compared to those of Zr-Sn-Fe-Cr. This can be explained by the second phase strengthening of the $\beta-\mathrm{Nb}$ precipitates. The creep test results indicate that the stress exponent for the steady-state creep rate decreases with the increase in the applied stress. However, the stress exponent of the $\mathrm{Zr}-\mathrm{Sn}-\mathrm{Fe}-\mathrm{Cr}$ alloy is lower than that of the $\mathrm{Zr}-\mathrm{Nb}-\mathrm{Sn}-\mathrm{Fe}$ alloy in a relatively high stress range, whereas the creep activation energy of the former is slightly higher than that of the latter. This can be explained by the dynamic deformation aging effect caused by the interaction of dislocations with Sn substitutional atoms. A higher Sn content leads to a lower stress exponent value and higher creep activation energy.
\end{abstract}

Key words creep, Zr-Nb-Sn-Fe, zircaloy-4, activation energy, dislocation, fracture, strength.

\section{1. 서 론}

$\mathrm{Zr}$ 합금은 높은 고온강도와 내식성을 갖고 있으며, 우수 한 기계적 특성 및 작은 중성자 흡수성으로 인하여 원자 로의 핵연료 피복관 및 구조재로 사용되고 있다. ${ }^{1)} \mathrm{Zr}$ 핵 연료 피복관은 핵분열 반응 시 $\mathrm{UO}_{2}$ 소결체에서 발생하는 핵 생성물 및 방사선을 일차적으로 막는 방호재 역할을 하며, 아울러 생성된 에너지를 효율적으로 외부로 전달 한다. $\mathrm{Zr}$ 핵연료 피복관은 내부에서의 핵분열 시 발생되 는 하중과 외부에서의 고온 냉각수로 인한 하중을 받고 있으므로, 원자로 가동의 안정성 측면에서 핵연료 피복 관에 대한 고온에서의 creep 거동 평가는 부식특성과 함께 가장 중요하게 고려해야할 사항중 하나이다. 한편, 제 1

\footnotetext{
Corresponding author

E-Mail : sihong@cnu.ac.kr (S. I. Hong)
}

세대 $\mathrm{Zr}$ 합금 피복관은 1960 년대 중반에 개발된 Zircaloy4 합금 $(\mathrm{Zr}-1.5 \mathrm{Sn}-0.2 \mathrm{Fe}-0.1 \mathrm{Cr})$ 으로써 수십년 동안 큰 문제 없이 사용되어 왔지만, 원전 운영자들에 의해 원전 안전 성 및 경제성 향상이 지속적으로 추구된 결과, Zircaloy4 합금에 비해 원자로내 연소성능이 상대적으로 우수한 제2세대 $\mathrm{Zr}$ 합금 피복관(Zirlo, $\mathrm{Mr}, \mathrm{MDA}, \mathrm{NDA}$ 등)이 1980 년대부터 미국, 프랑스 및 일본 등 원자력선진국 중 심으로 개발되었으며 Zirlo 및 M5 피복관 등은 현재 상 용 공급 중에 있다 제 2 세대 핵연료 피복관의 주요 첨가 원소로는 $\mathrm{Nb}$ 및 $\mathrm{Sn}$ 이 사용되고 있으며. 우리나라에서도 1990 년대 중반부터 제2세대 $\mathrm{Zr}$ 합금 피복관인 HANA 개 발에 착수하여 현재는 연구로 및 상용로에서 연료봉 단 위의 조사시험 중에 있다.

그동안 $\mathrm{Zr}$ 합금에 대한 creep특성에 대한 연구는 많이 수행되어 왔지만, 실험상의 어려움 때문에 대부분의 creep 특성 평가는 임의로 제조된 판재형 시편에 국한되어 실제 $\mathrm{Zr}$ 합금 피복관의 열처리 및 가공조직 등에 큰 차이가 
Table 1. Chemical composition of $\mathrm{Zr}$ alloys.

(wt.\%)

\begin{tabular}{ccccccc}
\hline \hline Element & $\mathrm{Nb}$ & $\mathrm{Sn}$ & $\mathrm{Fe}$ & $\mathrm{Cr}$ & $\mathrm{O}$ & $\mathrm{Zr}$ \\
\hline Zr-Sn-Fe-Cr & - & 1.36 & 0.21 & 0.11 & 0.12 & bal. \\
Zr-Nb-Sn-Fe & 1.00 & 1.00 & 0.10 & - & - & bal. \\
\hline
\end{tabular}

있었다. 따라서, 본 연구에서는 판재형 시편이 아닌, 링 형 피복관을 사용하여 $\mathrm{Zr}$ 합금 피복관 별 creep 특성을 비교 평가하였다. 즉 원자로내에서 연소도의 증가에 따라 핵연료 소결체의 열팽창과 팽윤, 핵분열 생성물 방출에 의해 피복관에 가해지는 응력이 주로 원주방향인 것을 고 려하여, 피복관의 길이방향에 수직으로 자른 링형 그립 을 제작하여 원주방향의 creep 거동을 연구하였다. 또한, 원자로 사고 시 핵연료 온도가 급격히 올라가는 경우에도 피복관 creep 거동을 정확히 예측하기 위해 원자로 정상 가동 온도보다 상대적으로 높은 온도에서도 creep 거동 을 연구하였다. 이러한 creep 시험을 통해 creep 변형기 구를 규명하였고, 피복관 시험시편의 미세조직 관찰을 통 해 creep 변형거동을 분석하였다. 또한 제 1 세대 및 제 2 세대 $\mathrm{Zr}$ 합금 피복관에 대한 creep 특성 비교 평가를 토 대로 하여 향후 새로운 $\mathrm{Zr}$ 합금 피복관의 개발 및 설계 시 활용될 기초자료를 생산하고자 하였다.

\section{2. 실험 방법}

본 연구에서는 응력이완 처리된(stress relieved) Zircaloy4 (Zr-Sn-Fe-Cr)(제1세대 합금) 및 $\mathrm{Zr}-\mathrm{Nb}-\mathrm{Sn}-\mathrm{Fe}$ 합금(제2 세대 합금) 등 2 종류의 튜브를 사용하였으며, 각 합금의 화학 조성은 Table 1에 나타내었다.

원주방향의 인장 및 creep 특성을 파악하기 위해 $\mathrm{Zr}$ 합금 피복관의 길이 방향에 수직으로 절단하여 $4 \mathrm{~mm}$ 반 지모양의 링형 시편을 제작하였다(Fig. 1). 가공중의 미세한 열적 변형을 최소화하기 위해 낮은 속도의 diamond saw 를 이용하여 절단하였으며, 시험 중에도 피복관의 원형 적인 형태를 유지할 수 있도록 특수한 그립이 사용되었다.

$\mathrm{Hong}^{2}$ 등은 $\mathrm{Zr}$ 합금 피복관의 인장시험을 통해 축방 향과 원주방향의 기계적 강도가 유사하다는 것과 축방향 인장시험을 토대로 하여 링형 시편의 gauge 길이를 결정 하였음을 보고하였다. 부연하면, $\mathrm{Hong}^{2}$ 등은 gauge 길이 를 $5 \mathrm{~mm}$ 로 정하였을 경우 연성, 변형율 속도 등이 기 준치와 일치하였고 실제 변형은 $5 \mathrm{~mm}$ 이내로 국한되었 음을 보고하였다. 이에 따라 본 실험에서는 gauge 길이 를 $5 \mathrm{~mm}$ 로 정하였고, $\mathrm{Zr}$ 합금 피복관의 creep 변형을 유발하는 creep 변형 기구를 정확히 규명하기 위해 일정 응력 방식의 creep 시험기를 사용하였다. 본 실험은 450 $500^{\circ} \mathrm{C}$ 및 $80 \sim 1500 \mathrm{MPa}$ 에서 수행되었다. creep에 의한 변형은 LVDT (Linear Variable Differential Trans-
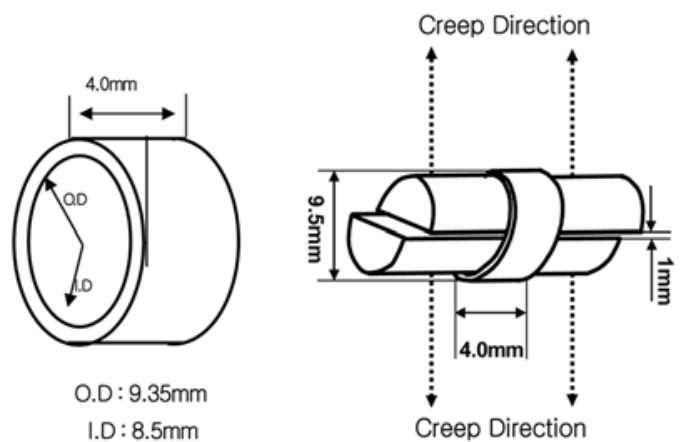

Fig. 1. Schematic configuration of tensile and creep test sample (a) ring specimen and (b) grip configuration.

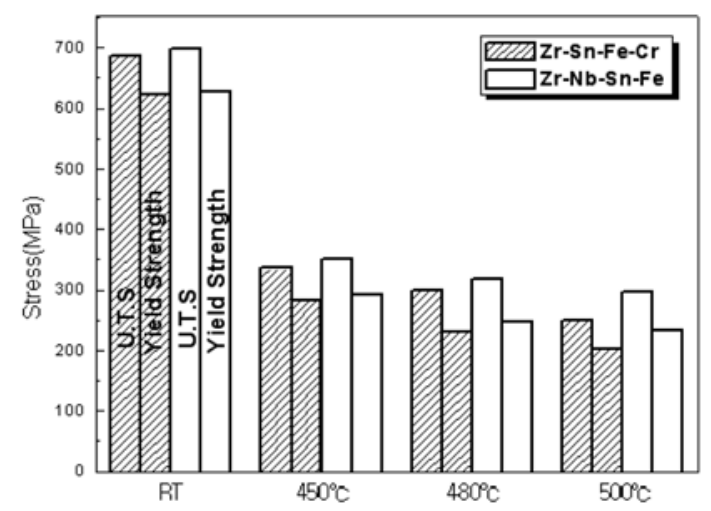

Fig. 2. Yield strength and U.T.S on $\mathrm{Zr}$ alloys.

former)를 이용하여 출력 전압을 Signal conditioner를 통해 증폭시켜 연결된 recoder에 기록하여 정상상태 creep 속도 $\mathrm{s}$ 를 구하였다.

Creep 파단기구를 규명하기 위해 creep 시험 후, 파단된 시편을 아세톤 용액에 초음파로 세척하였고, 주사전자현 미경(SEM)을 이용하여 파단조직을 관찰하였다. 전위 및 석출물 거동을 분석하기 위해서, 파단되지 않은 2 차 구 간의 creep 시편을 $70 \mu \mathrm{m}$ 까지 $\mathrm{SiC}$ 연마지로 우선 연마 한 후, 펀치로 지름 $3 \mathrm{~mm}$ 디스크 형태의 시편을 제작하 였다. 이 디스크형 시편을 과염소산 $10 \%$ 과 에탄올을 혼 합한 용액을 Twin Jet Polisher 사용하여 $-40 \sim 45^{\circ} \mathrm{C}$, 인 가전압 12 $20 \mathrm{~V}$ 하에서 전해연마를 실시하여 박판 시편 을 제작하였다. 이와 같이 제작된 시편을 $200 \mathrm{kV}$ 가속전 압의 TEM(JEOL-2010) 장비를 사용하여 관찰하였고, 석 출물의 화학적 성분 분석은 $\mathrm{TEM}$ 에 부착된 $\mathrm{EDS}$ 장비를 이용하였다. 


\section{3. 결과 및 고찰}

Fig. 2는 각 합금의 열처리 온도에 따른 상온 및 고온 에서의 최대인장강도 및 항복강도 변화를 나타낸 것이다. 두 종류의 합금 모두 상온에 비해 열처리 온도가 증가 할수록, 최대인장강도 및 항복강도가 감소하는 일반적인 냉간가공 금속의 특성을 나타내고 있다. 상온에서와 고온 에서의 인장강도가 큰 차이를 보이는 것은 고온의 열처 리와 더불어 진행되는 전위의 이동과 재배열에 따라 전위 의 소멸과 전위밀도의 감소가 초래되었고, 이에 따라 교 차슬립 및 전위 상승이 용이하게 되어 $\mathrm{Zr}$ 합금 내부 응 력이 저하되기 때문인 것으로 판단된다. 한편, 그림 2에서 보듯이 온도가 증가할수록 $\mathrm{Zr}-\mathrm{Nb}-\mathrm{Sn}-\mathrm{Fe}$ 합금의 인장강도 및 항복강도가 $\mathrm{Zr}-\mathrm{Sn}-\mathrm{Fe}-\mathrm{Cr}$ 합금에 비해 약간씩 증가하고 있음을 볼 수 있다. 이는 $\mathrm{Zr}-\mathrm{Nb}-\mathrm{Sn}-\mathrm{Fe}$ 합금에 존재하는 $\beta-\mathrm{Nb}$ 석출물에 의한 강화효과에 기인한 것으로 추정된다.

Fig. 3에는 각각의 합금에 대해 일정응력조건의 creep 시험을 통하여 초기 변형량을 제외한 시간에 따른 원주 방향의 creep 변형량이 나타나있다. 두 합금 모두 전 구간 에 걸쳐 전형적인 1,2 및 3 차 구역을 갖는 creep 변형 곡 선을 보여주고 있다. 일반적으로 $\mathrm{Zr}$ 합금 피복관의 creep 변형속도는 최종 열처리, 냉간가공도 및 합금원소의 영 향을 받는 것으로 알려져 있다. 그림 4 에는 $450^{\circ} \mathrm{C}, 480$, $500^{\circ} \mathrm{C}$ 등 각 시험온도에 따른 두 합금의 creep 변형속도 가 나타나있다. 이 그림에서 보듯이 온도 및 응력이 증가 할수록 정상상태 creep rate가 증가하고 있으며, $\mathrm{Nb}$ 이 첨 가된 제 2 세대 함금인 $\mathrm{Zr}-\mathrm{Nb}-\mathrm{Sn}-\mathrm{Fe}$ 에 비해 제1세대 합금 인 $\mathrm{Zr}-\mathrm{Sn}-\mathrm{Fe}-\mathrm{Cr}$ 의 creep 저항성이 상대적으로 높게 나타 나고 있다.

일반적으로 $\mathrm{Sn}$ 은 $\mathrm{Zr}$ 기지내에서 치환형 고용체로 존재 하며, $\mathrm{Sn}$ 과 $\mathrm{Zr}$ 의 원자반경 차이에 의해서 격자 뒤틀림을 유발하여 발생하는 응력장이 전위나 공공의 이동을 방해 하는 주요 장애물의 역할을 하는 것으로 알려져 있다. ${ }^{3)}$ 또한 $\mathrm{Sn}$ 은 $\mathrm{Zr}$ 기지내의 적층결함에너지를 감소시키는 역 할을 하는 것으로 보고되고 있다. ${ }^{4)}$ 적층결함은 부분전위 로 둘러싸여 있으며, 적층결함의 폭은 적층결함에너지에 반비례함을 감안하면. 상대적으로 낮은 적층결함에너지를 갖는 경우에는 부분전위들 간의 간격을 넓어져서 전위 상 승 또는 cross slip을 억제함으로써 creep 강도를 향상시 킨다. 따라서 $\mathrm{Sn}$ 은 creep 속도 감소에 영향을 주는 주요 함금 원소이며, 그 결과 $\mathrm{Zr}-\mathrm{Nb}-\mathrm{Sn}-\mathrm{Fe}$ 합금에 비해 $\mathrm{Sn}$ 함량이 높은 $\mathrm{Zr}-\mathrm{Sn}-\mathrm{Fe}-\mathrm{Cr}$ 합금의 creep 저항성이 상대적 으로 우수하게 나타난 것으로 판단된다. $\mathrm{Zr}-\mathrm{Nb}-\mathrm{Sn}-\mathrm{Fe}$ 합 금에 첨가되어 있는 $\mathrm{Nb}$ 의 고용한계는 $0.6 \mathrm{wt} . \%$ 로 매우 낮아서 고용한계까지는 고용강화효과를 보이지만, 그 이 상의 첨가 시에는 $\beta-\mathrm{Nb}$ 석출물로 존재하여 석출강화효 과를 갖는다. ${ }^{5} \mathrm{Zr}-\mathrm{Sn}-\mathrm{Fe}-\mathrm{Cr}$ 합금의 높은 $\mathrm{Sn}$ 함량에 의한
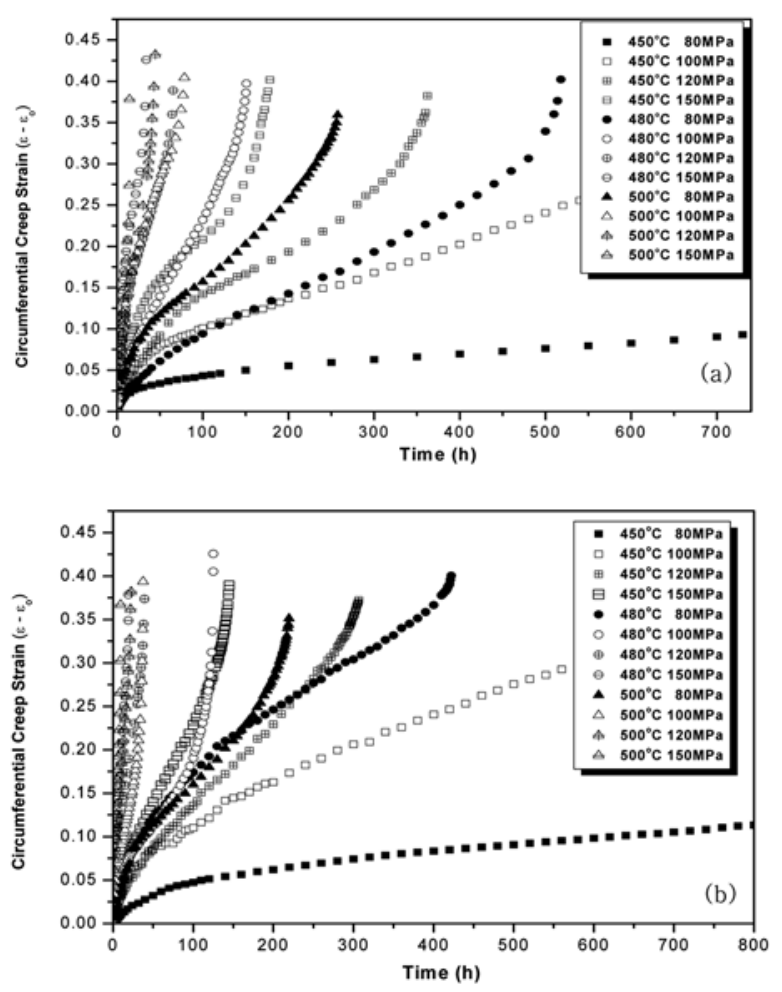

Fig. 3. Creep curves generated by applied stress on $\mathrm{Zr}$ alloys at 450,480 and $500^{\circ} \mathrm{C}$, respectively (a) $\mathrm{Zr}-\mathrm{Sn}-\mathrm{Fe}-\mathrm{Cr}$ and (b) $\mathrm{Zr}-\mathrm{Nb}$ Sn-Fe.

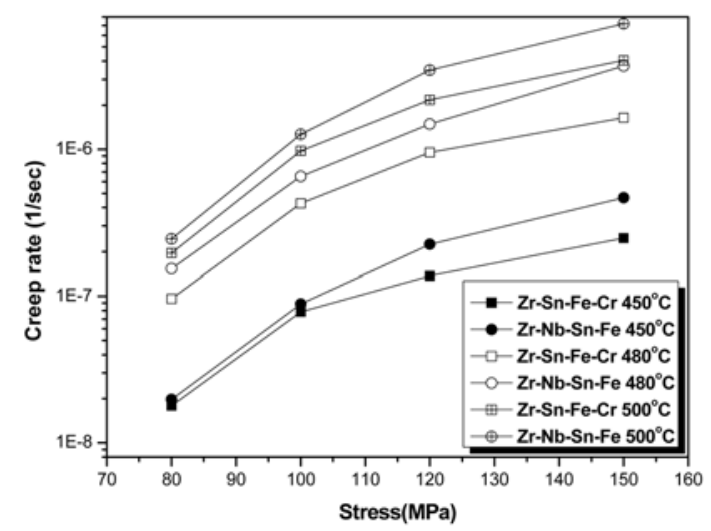

Fig. 4. Effect of stress and temperature on steady state creep strainrates of $\mathrm{Zr}-\mathrm{Sn}-\mathrm{Fe}-\mathrm{Cr}$ and $\mathrm{Zr}-\mathrm{Nb}-\mathrm{Sn}-\mathrm{Fe}$ cladding tubes.

고용강화효과가 $\mathrm{Zr}-\mathrm{Nb}-\mathrm{Sn}-\mathrm{Fe}$ 합금의 $\mathrm{Nb}$ 의 고용강화효과 및 또는 $\mathrm{Nb}$ 석출물 강화효과에 비해 더 크게 작용했기 때문이라 생각된다.

Fig. 2의 인장시험 결과와 Fig. 3의 creep 시험 결과를 비교해 보면, $\mathrm{Zr}-\mathrm{Sn}-\mathrm{Fe}-\mathrm{Cr}$ 합금의 기계적 강도는 $\mathrm{Zr}-\mathrm{Nb}-$ $\mathrm{Sn}-\mathrm{Fe}$ 에 비해 낮지만 creep 저항성은 오히려 크게 나타 났다. 이는 각 합금에 첨가되어 있는 $\mathrm{Sn}$ 용질원자의 함량 과 creep 조건에서의 전위 이동속도와의 상호작용과 관련 된다. 즉 인장시험의 변형속도는 $1.33 \times 10^{-3}$ 인 반면, creep 
시험의 변형속도는 보통 $10^{-7} \sim 10^{-8}$ 로써 creep 변형속도는 인장시험 변형속도에 비해 매우 작음을 알 수 있다. 따 라서, 인장시험 경우에는 전위이동속도에 비해 $\mathrm{Sn}$ 용질 원자의 확산속도가 낮아 전위와 함께 쉽게 이동할 수 없 어 전위가 용질원자 분위기를 쉽게 벗어남으로써 $\mathrm{Sn}$ 용 질원자가 강한 drag force로 작용할 수 없지만, creep 시 험에서는 용질원자의 이동속도와 전위이동속도에 큰 차 이가 없으므로 $\mathrm{Sn}$ 이 전위에 고착하여 drag force로 작 용할 수 있다. 따라서 $\mathrm{Sn}$ 이 $1.36 \mathrm{wt} . \%$ 함유되어 있는 $\mathrm{Zr}-\mathrm{Sn}-\mathrm{Fe}-\mathrm{Cr}$ 합금은 $1.00 \mathrm{wt} . \%$ 함유되어 있는 Zr-Nb-Sn$\mathrm{Fe}$ 합금에 비해 creep 저항성이 큰 것으로 사료된다.

일반적으로 creep은 전위의 점진적인 이동에 의하여 변 형을 유발하는 것으로 시간이 경과함에 따라 일어나는 열 적 활성화 과정에 의한 소성변형이며, creep 변형속도는 응력의 지수함수로 나타나고 아래와 같은 Power law creep 식(1)으로 표현될 수 있다.)

$$
\dot{\varepsilon}=B D \sigma^{n}=A \sigma^{n} \exp \left(-Q_{c} / R T\right)
$$

여기서 $\dot{\varepsilon}$ 는 steady-state creep rate, $\sigma$ 은 적용응력, $A, B$ 는 재료특성에 관련되는 상수, $n$ 은 응력지수, $Q_{c}$ 는creep 변형에 필요한 활성화 에너지, $R$ 은기체상수, $T$ 는 절대온 도이다.

응력지수 $n$ 은 일정온도에서의 응력의 함수로써 $\log \varepsilon$ $-\log \sigma$ 그래프의 기울기로부터 구할 수 있다. 본 연구에서 얻어진 creep rate를 수식 (1)에 적용하여 각 $\mathrm{Zr}$ 합금에 대한 응력지수를 구하였고(Fig. 5 참조). 그 결과로부터 응력이 creep 변형속도에 미치는 영향을 분석하였다. Fig. 5 에서 보듯이 $\mathrm{Zr}-\mathrm{Sn}-\mathrm{Fe}-\mathrm{Cr}$ 합금에서는 응력지수값이 저 응력구간에서 대략 6 7을 나타내다가, 고 응력구간에서 는 응력지수값이 약 3으로 감소하였다. 또한, $\mathrm{Zr}-\mathrm{Nb}-\mathrm{Sn}-$ $\mathrm{Fe}$ 합금에서는 응력지수값이 저 응력구간에서 대략 6 7 을 나타내다가, 고 응력구간에서는 응력지수값이 약 4로 감소하였다. 이와 같이 고 응력범위에서 응력지수값이 감 소하는 현상은 $\mathrm{Hong}^{2}$ 등이 제시한 바와 같이 $\mathrm{Zr}-\mathrm{Sn}-\mathrm{Fe}-$ $\mathrm{Cr}$ 및 $\mathrm{Zr}-\mathrm{Nb}-\mathrm{Sn}-\mathrm{Fe}$ 합금에 포함되어 있는 용질원자 $\mathrm{Sn}$ 의 확산과 전위의 상호작용에 따른 동적변형시효 현상에 기인한 것으로 판단된다. $\mathrm{Sn}$ 의 함량이 많은 $\mathrm{Zr}-\mathrm{Sn}-\mathrm{Fe}-\mathrm{Cr}$ 합금에서 응력지수의 변화가 더 급격하게 감소한 것은 $\mathrm{Hong}$ 의 동적변형시효 모델의 예측결과와 일치한다. 즉 $\mathrm{Sn}$ 의 함량이 많을수록 전위에 작용하는 drag force가 상대 적으로 더 크게 증가하여 응력지수를 더 많이 낮춘다.

Creep 변형에 필요한 활성화 에너지는 수식 (1)에서 Arrhennius의 속도식을 이용하여 구할 수 있다. ${ }^{6)}$ 즉 creep 변형에 필요한 활성화 에너지 $Q_{c}$ 는 수식(1)을 사용 하여 $-\mathrm{R}\left[(\delta \ln \varepsilon / \delta(1 / \mathrm{T})]_{\sigma}\right.$ 로서 구할 수 있다. 본 연구에서 는 일정 응력방식으로 각 온도 및 응력 구간에서의 정 상상태 creep 변형속도 $(\dot{\varepsilon})$ 를 측정한 후 $1 / T$ 와 $\ln \dot{\varepsilon}$ 의 직
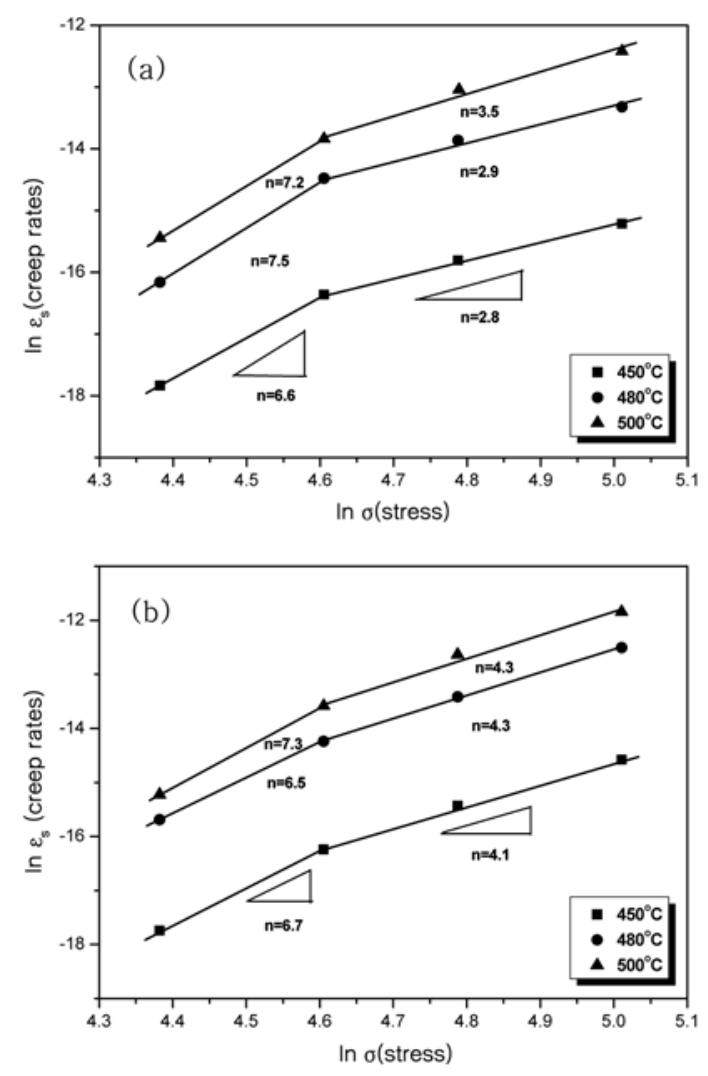

Fig. 5. Relationships of steady state creep rate and stress for $\mathrm{Zr}$ alloys at 450,480 and $500^{\circ} \mathrm{C}$, respectively (a) $\mathrm{Zr}-\mathrm{Sn}-\mathrm{Fe}-\mathrm{Cr}$ and (b) $\mathrm{Zr}-\mathrm{Nb}-\mathrm{Sn}-\mathrm{Fe}$.

선 관계로부터 $Q_{c}$ 를 구하였다(Fig. 6). Fig. 6에서 보듯이 $\mathrm{Zr}$ 합금 종류와 상관없이 응력이 증가함에 따라 활성화 에너지도 미미하게 증가하고 있으며, 이는 $\mathrm{Sn}$ 용질원자에 의한 동적변형시효 영향에 의한 것으로 판단된다. 실제 로 Hong은 응력지수가 감소하는 고 응력구간에서 동적 변형시효에 의하여 응력지수가 감소하고 활성화 에너지 가 증가할 수 있음을 제시하였다.

아래와 같은 power-law creep 관계식을 이용하여 각 합금에 대한 $\ln \dot{\varepsilon} / \mathrm{D}$ 과 $\sigma / \mathrm{E}$ 와의 관계를 나타낼 수 있다.

$$
\left.\dot{\varepsilon}=B \mathrm{D \sigma}^{n}=A \sigma \mathrm{n} \exp \left(-Q_{d} / R T\right)\right)
$$

여기서 $\dot{\varepsilon}$ 는 steady-state creep rate, $\sigma$ 은 적용응력, $A$, $B$ 는 재료특성에 관련되는 상수, $n$ 은 응력지수, $Q_{c}$ 는creep 변형에 필요한 활성화 에너지, $R$ 은 기체상수, $T$ 는 절대 온도이다.

각 합금에 대한 $\ln \dot{\varepsilon} / \mathrm{D}$ 과 $\sigma / \mathrm{E}$ 와의 관계는 Fig. 7 에 나 타나 있다. 이 그림에서 보듯이 $\ln \dot{\varepsilon} / \mathrm{D}$ 과 $\sigma / \mathrm{E}$ 의 관계는 실험온도에 무관하게 하나의 선으로 나타낼 수 있으며, 응력의 증가함에 따라 기울기가 감소하고 있음을 알 수 있다. 상기와 같이 본 creep 시험을 통해 $\mathrm{Zr}-\mathrm{Sn}-\mathrm{Fe}-\mathrm{Cr}$ 합금의 경우, 응력증가에 따라 응력지수가 6 7에서 약 3 

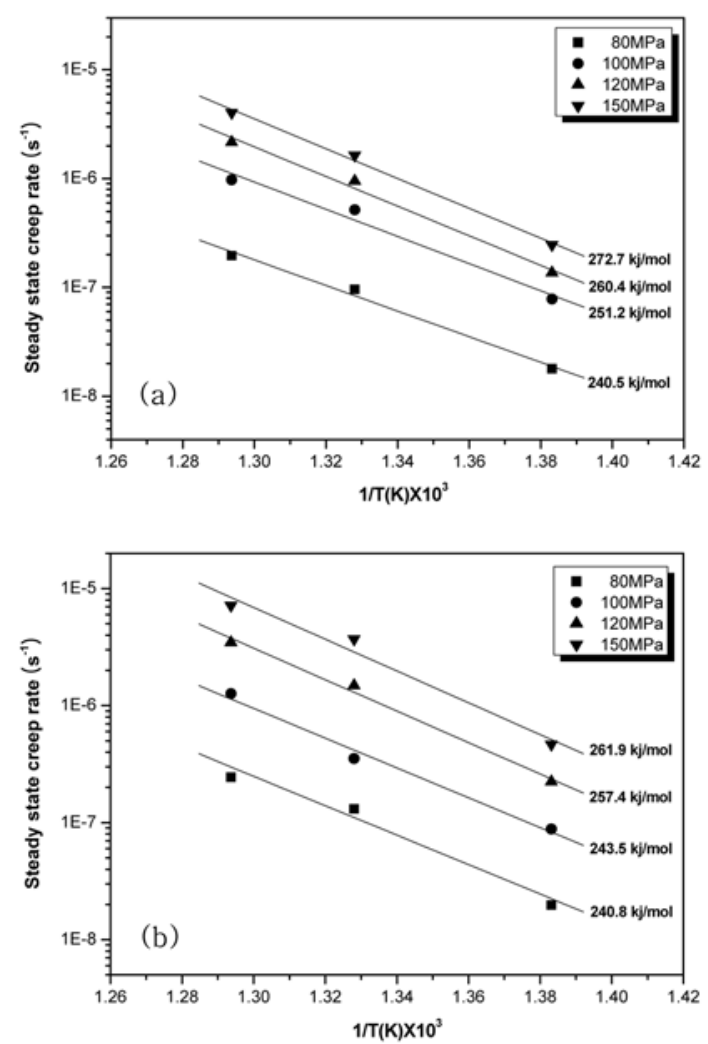

Fig. 6. Relationships of steady state creep rate and $1 / \mathrm{T}$ for $\mathrm{Zr}$ alloys at 450,480 and $500^{\circ} \mathrm{C}$, respectively (a) $\mathrm{Zr}-\mathrm{Sn}-\mathrm{Fe}-\mathrm{Cr}$ and (b) $\mathrm{Zr}-\mathrm{Nb}-\mathrm{Sn}-\mathrm{Fe}$.

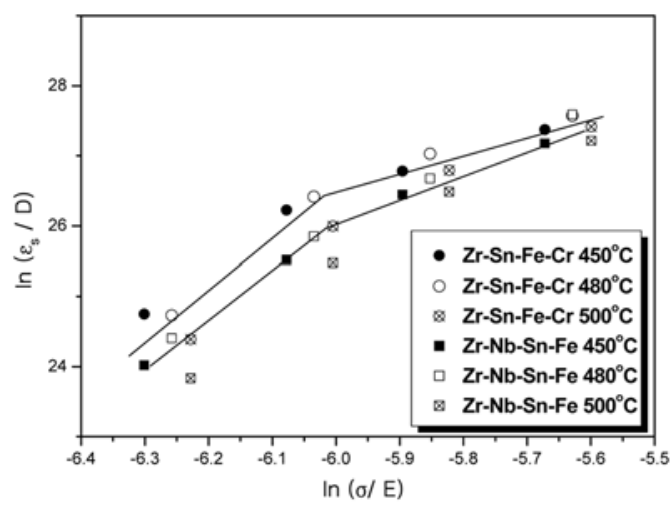

Fig. 7. Temperature compensated creep rate vs elastic modulus compensated applied stress, based on Dorn-type creep model.

으로 감소하였으며, $\mathrm{Zr}-\mathrm{Nb}-\mathrm{Sn}-\mathrm{Fe}$ 합금도 응력지수가 6 7 에서 약 4로 감소하였다. Murty ${ }^{7}$ 등은 $\mathrm{Zr}-\mathrm{Nb}-\mathrm{Sn}-\mathrm{Fe}$ 합 금과 조성이 비슷한 $\mathrm{Zr}-1 \mathrm{Nb}-1 \mathrm{Sn}-0.2 \mathrm{Fe}$ 합금에 관해 응력 지수값에 따라 creep 변형기구의 변화를 설명하였다. 즉 Muty 등은 $500 \sim 700^{\circ} \mathrm{C}$ 에서 $20 \sim 140 \mathrm{MPa}$ 의 creep 시험을 통해 $n=1$ 일 때는 Nabbaro-Herring과 Coble creep과 같은 격자나 결정입계를 통해 응력에 따른 공공의 확산에 의한 creep 기구, $n=3$ 일 때는 Weertman ${ }^{8)}$ 등이 제시한 용질
원자 고용강화 합금에서의 creep과 유사한 칼날전위의 점 성 glide에 의해 지배되는 cree 기구, $n=5 \sim 7$ 에서는 칼날전 위의 상승(climb)에 의한 creep 기구가 작용하고 있다고 보고하였다. 본 실험에서 구한 활성화 에너지는 대략 240 270 kJ/mol로써 Kidson ${ }^{9}$ 과 Murty ${ }^{10)}$ 등에 의해 보고된 활성화 에너지와 거의 일치하는 것을 알 수 있다. 그러 나 본 연구에서는 활성화 에너지 값이 응력이 증가함에 따라 $\mathrm{Zr}-\mathrm{Sn}-\mathrm{Fe}-\mathrm{Cr}$ 합금의 경우에는 $240 \mathrm{~kJ} / \mathrm{mol}$ 에서 $270 \mathrm{~kJ} / \mathrm{mol}$ 로, $\mathrm{Zr}-\mathrm{Nb}-\mathrm{Sn}-\mathrm{Fe}$ 합금의 경우에는 $240 \mathrm{~kJ} / \mathrm{mol}$ 에서 $260 \mathrm{~kJ} / \mathrm{mol}$ 로 증가하였다. 이러한 결과로 볼 때 두 합금 모두 저 응력 구간에서는 칼날전위 climb에 의한 creep 기구가 크립 율속기구이지만 고 응력구간에서는 Weertman이 제시한 칼날전위의 점성활주가 율속기구에 기 여하고 있는 것으로 판단된다. 실제로 Hong ${ }^{11-15)}$ 은 응력 지수가 감소하는 고 응력구간에서 동적변형시효에 의하여 응력지수가 감소하고 활성화 에너지가 증가할 수 있음을 제시하였다. 이는 Oikawa 등 ${ }^{16)}$ 이 제시한 $\mathrm{Mg}$ 의 강화효 과가 있는 $\mathrm{Al}-\mathrm{Mg}$ 합금의 creep 실험결과와 일치한다. 따 라서 $\mathrm{Sn}$ 의 함량이 많은 $\mathrm{Zr}-\mathrm{Sn}-\mathrm{Fe}-\mathrm{Cr}$ 합금의 경우 동적 변형시효 효과에 의해 고 응력구간에서는 $\mathrm{Sn}$ 에 의한 큰 drag force가 발생하여 $\mathrm{Sn}$ 함량이 상대적은 적은 $\mathrm{Zr}-\mathrm{Nb}-$ $\mathrm{Sn}-\mathrm{Fe}$ 합금에 비해 응력지수값을 더 감소시키고 활성화 에너지를 더 증가시키는 것으로 보인다.

Fig. 8 에는 $480^{\circ} \mathrm{C}, 80 \mathrm{MPa}$ 의 creep 시험에서 추출한 정상상태 creep 영역의 각 $\mathrm{Zr}$ 합금 시편에 대해 투과전 자현미경(TEM)을 이용하여 전위 및 석출물을 고배율로 관찰한 결과가 나타나 있다. 두 합금 모두 장시간의 고온 의 creep 변형으로 전위들이 생성 및 재배열되어 아결 정립의 합체 및 성장이 일어나 재결정 조직이 많이 발 달되어 있음을 알 수 있다. 조직내에 둥근 형태의 작은 석출물들이 불균일하게 분포되어 있고, 두 합금 모두 석 출물 크기에 큰 차이가 없는 것으로 보이며, 이러한 석 출물들이 전위에 이동을 방해하는 데 역할을 하는 것으로 판단된다.

Fig. 8(a)에서는 $\mathrm{Zr}-\mathrm{Sn}-\mathrm{Fe}-\mathrm{Cr}$ 합금의 전위 tangle들이 석출물 주위에서 관찰되었으며, 재결정으로 인해 조대해 진 결정립계(grain boundary)에 둥근 형태에 석출물이 분 포되어 있음을 볼 수 있다. 일반적으로 $\mathrm{Zr}-\mathrm{Sn}$-Fe-Cr합금 에서는 $\mathrm{Zr}(\mathrm{Fe}, \mathrm{Cr})_{2}$ 석출물이 관찰되며, 이런 석출물의 크 기와 분포는 부식 성질과 매우 밀접한 관계가 있는 것 으로 알려져 있다. ${ }^{18)} \mathrm{Fig}$. 8(c)에서 보듯이 $\mathrm{Zr}-\mathrm{Nb}-\mathrm{Sn}-\mathrm{Fe}$ 합금의 경우 전위 tangle 및 전위 pile-up이 관찰되었으 며, 석출물이 결정립내뿐만 아니라 결정립계에도 형성되어 고루 분포하고 있음을 알 수 있다. Zr-Nb-Sn-Fe 합금의 경우 $\mathrm{EDS}$ 분석에 의하여 $\beta-\mathrm{Nb}$ 석출상이 확인되었으며 $\mathrm{Fe}$ 의 성분을 갖고 있는 석출물도 관찰할 수 있었다. 이는 상용 $\mathrm{Zr}-\mathrm{Nb}-\mathrm{Sn}-\mathrm{Fe}$ 합금에서 $\beta-\mathrm{Nb}$ 상과 $\mathrm{ZrNbFe}$ 상이 


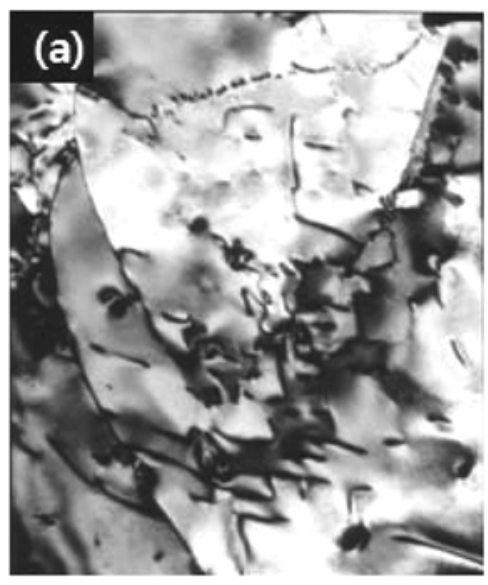

(a)

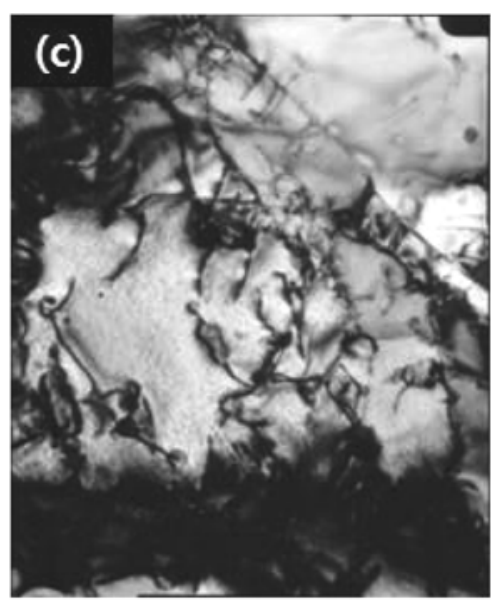

(c)

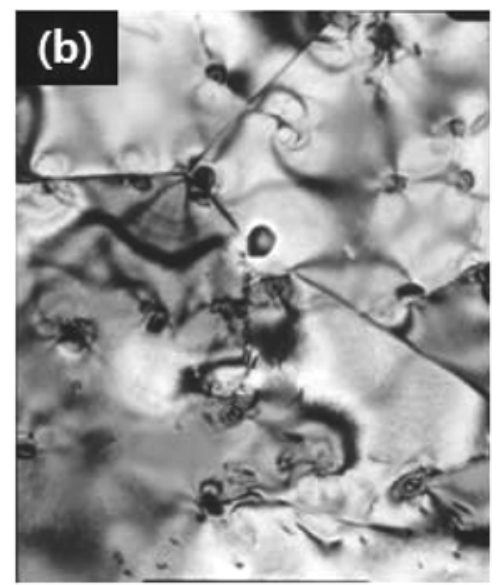

(b)

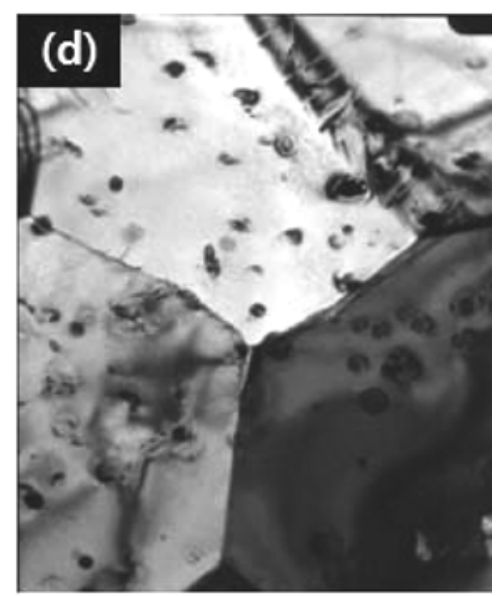

(d)

Fig. 8. TEM micrographs of $\mathrm{Zr}-\mathrm{Sn}-\mathrm{Fe}-\mathrm{Cr}$ and $\mathrm{Zr}-\mathrm{Nb}-\mathrm{Sn}-\mathrm{Fe}$ alloys at $480^{\circ} \mathrm{C}$, respectively (a) Dislocation $(\times 50 \mathrm{~K})$, (b) Precipitation $(\times 50) \mathrm{Zr}-\mathrm{Sn}-\mathrm{Fe}-\mathrm{Cr}$ and $(\mathrm{c})$ Dislocation $(\times 50 \mathrm{~K})$ and $(\mathrm{d})$ Precipitatin $(\times 50)$ of $\mathrm{Zr}-\mathrm{Nb}-\mathrm{Sn}-\mathrm{Fe}$ alloys.

석출된다는 보고 ${ }^{39-40)}$ 와 일치한다.

원자로 내에서 장시간의 운전에 따라 안정성 및 경제 적인 측면에서 피복관의 대한 수명 예측 및 평가는 절 대적으로 필요하다. creep 변형속도와 파단 시간과의 관 계를 검토해보면 가해진 온도와 응력이 증가할수록 creep 수명이 급격히 감소하고 있다는 것을 알 수 있다. 특정 온도에서 파단시간이 주어지면 다른 온도에서의 파단 시 간을 예측할 수 있다. creep 수명을 예측하는 방법'으로는 Larson-Miller Parameter, Orr-Sherby-Dorn Parameter, Manson-Haferd parameter 및 Manson-brown parameter 등이 있다. 본 연구에서는 비교적 간단하면서 정확하기 때문에 널리 쓰는 Larson-Miller Parameter (LMP)를 이 용하였다.

$$
\mathrm{LMP}=\mathrm{T}\left\{C+\log \left(t_{r}\right)\right\}
$$

여기서 $\mathrm{T}$ 는 화씨온도 $\left({ }^{\circ} \mathrm{F}\right)$ 의 절대값인 ${ }^{o} \mathrm{R}, \mathrm{t}_{\mathrm{r}}$ 은 파단시 간(hr), $C$ 는 재료상수값이다. $C$ 는 17 23 범위의 값 ${ }^{17)}$ 을

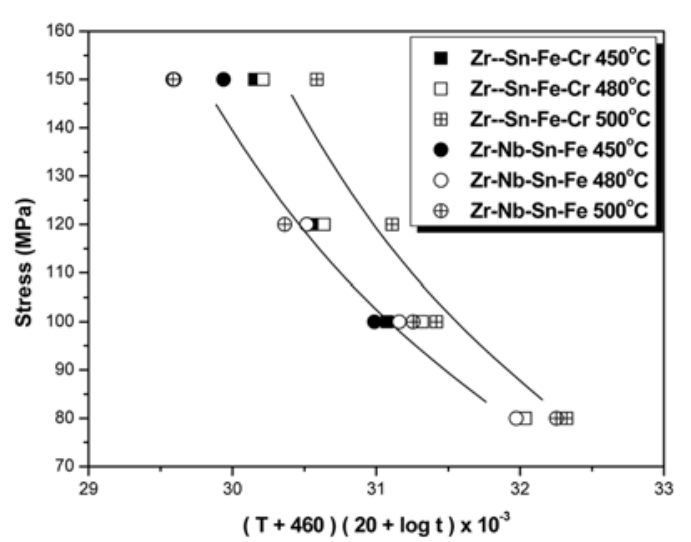

Fig. 9 Larson-Miller Parameters of $\mathrm{Zr}$ alloys.

가지고 있으며 본 연구에서는 20 을 사용하였다.

Fig. 8에는 두 종류의 $\mathrm{Zr}$ 합금에 대하여 수식 (3)에 의해 온도에 무관하게 구한 $\mathrm{LMP}$ 와 응력과의 관계가 나타나 


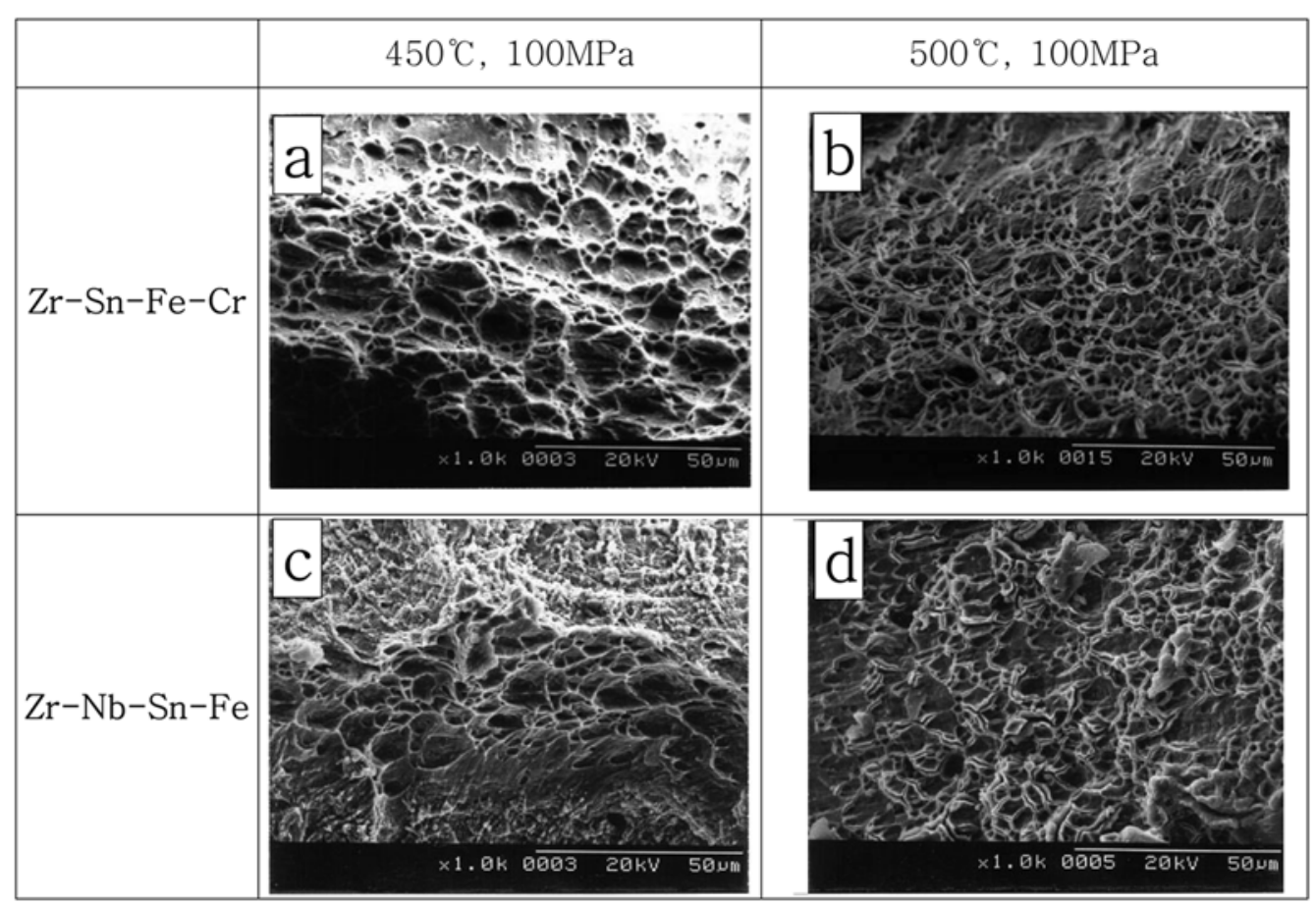

Fig. 10. SEM images of crept $\mathrm{Zr}$ alloys (a) $\mathrm{Zr}-\mathrm{Sn}-\mathrm{Fe}-\mathrm{Cr}, 450^{\circ} \mathrm{C}, 500 \mathrm{Mpa}$, (b) $\mathrm{Zr}-\mathrm{Sn}-\mathrm{Fe}-\mathrm{Cr}, 450^{\circ} \mathrm{C}, 500 \mathrm{Mpa},(\mathrm{C}) \mathrm{Zr}-\mathrm{Nb}-\mathrm{Sn}-\mathrm{Fe}$, $500^{\circ} \mathrm{C}, 500 \mathrm{Mpa}$ and (d) $\mathrm{Zr}-\mathrm{Nb}-\mathrm{Sn}-\mathrm{Fe}, 500^{\circ} \mathrm{C}, 500 \mathrm{Mpa}$.

있다. 이 그림에서 보듯이 응력이 증가함에 따라 LMP 가 감소하는 일반적인 경향이 나타나고 있으며, 상수 $C$ 값은 본 실험구간에서 대체로 잘 적용되고 있음을 알 수 있다.

고온 creep 시험 후에, 각 $\mathrm{Zr}$ 합금에 대하여 creep 파단 면을 SEM으로 관찰한 결과를 Fig. 10에 나타내었다. Fig. 10에서 보듯이 모든 실험온도구간에서 분화구 모양의 움푹 파인 독특한 조직인 dimple이 관찰되고 있다. 일 반적으로 전형적인 연성파괴인 dimple은 주로 미소 공 동의 발생, 성장 및 합체에 의해 일어나며, 온도가 올라 갈수록 dimple의 크기도 커지는 경향을 볼 수 있다.

Fig. $10(\mathrm{a}, \mathrm{c})$ 에서 $450^{\circ} \mathrm{C} 100 \mathrm{MPa}$ 의 creep 파단면을 보 면, 두 합금 모두 결정립 내부를 통한 입내파괴가 나타 났으며, 응력이 높을수록, 결정립계를 따르는 2차 균열 이 발달되는데, 온도가 높아질수록 열적 평형 공공의 수 가 증가하고, 또한 확산이 용이해지므로 결정립계로 더 욱 많은 공공 혹은 불순물들이 확산하여 입내에서 입계 파괴로 천이되는 것으로 판단된다. 상대적으로 높은 온 도에서 시험한 $500^{\circ} \mathrm{C} 100 \mathrm{MPa}$ 의 경우에는 파단면에서 결정립계를 통한 2차파괴 형태가 증가하였음을 알 수 있 다(Fig. $10(\mathrm{~b}, \mathrm{~d}))$. 금속이나 합금의 creep 파단은 거의가 cavity들의 형성에 의해서 이루어지고 이러한 cavity들이 생성과 합체를 유발하여 결국 입계 주위에 모여진 cavity 가 궁극적으로 파단에 이르게 된다.

\section{4. 결 론}

본 연구에서는 $\mathrm{Zr}-\mathrm{Sn}-\mathrm{Fe}-\mathrm{Cr}$ 합금과 $\mathrm{Zr}-\mathrm{Nb}-\mathrm{Sn}-\mathrm{Fe}$ 합금에 대하여 상온 $~ 500^{\circ} \mathrm{C}$ 의 온도범위에서 기계적강도 시험과 $450 \sim 500^{\circ} \mathrm{C}$ 의 온도범위, $80 \sim 1500 \mathrm{MPa}$ 의 응력범위에서 원 주방향 creep 시험을 수행하였고 시험결과를 비교 분석한 결과, 다음과 같은 결론을 얻었다.

1) 두 합금 모두 상온에 비해 열처리 온도가 증가할 수록, 최대 인장강도 및 항복강도가 감소하는 일반적인 냉간가공 금속의 특성을 나타내었다. 이는 실험온도가 증 가할수록 전위의 이동과 재배열의 의해 전위가 소멸하고 전위밀도가 감소함에 따라 교차슬립 및 전위 상승이 용이 하게 되어 $\mathrm{Zr}$ 합금 내부 응력이 저하되기 때문이다. 또 한 실험온도가 증가할수록 $\mathrm{Zr}-\mathrm{Nb}-\mathrm{Sn}-\mathrm{Fe}$ 합금의 인장강도 및 항복강도가 $\mathrm{Zr}-\mathrm{Sn}-\mathrm{Fe}-\mathrm{Cr}$ 합금에 비해 약간씩 증가하 였다. 이는 $\mathrm{Zr}-\mathrm{Nb}-\mathrm{Sn}-\mathrm{Fe}$ 합금에 존재하는 용질원자 $\mathrm{Nb}$ 및 $\beta-\mathrm{Nb}$ 석출물에 의한 강화효과에 기인한 것으로 판 단된다.

2) 본 연구의 온도 및 응력 구간에서, $\mathrm{Zr}-\mathrm{Sn}-\mathrm{Fe}-\mathrm{Cr}$ 합금 이 $\mathrm{Zr}-\mathrm{Nb}-\mathrm{Sn}-\mathrm{Fe}$ 합금에 비해 creep 저항성이 크게 나타 났다. 이는 $\mathrm{Zr}-\mathrm{SN}-\mathrm{Fe}-\mathrm{Cr}$ 합금에서의 높은 함량의 $\mathrm{Sn}$ 의 고용강화효과가 $\mathrm{Zr}-\mathrm{Nb}-\mathrm{Sn}-\mathrm{Fe}$ 합금에서의 용질원자 $\mathrm{Nb}$ 및 $\beta-\mathrm{Nb}$ 석출물에 의한 강화효과보다 더 크게 작용한 것으로 추정된다. 
3) $\mathrm{Zr}-\mathrm{Sn}-\mathrm{Fe}-\mathrm{Cr}$ 합금에서는 응력지수값이 저 응력구간 에서 대략 6 7을 나타내다가, 고 응력구간에서는 응력지 수값이 약 3으로 감소하였으며, $\mathrm{Zr}-\mathrm{Nb}-\mathrm{Sn}-\mathrm{Fe}$ 합금에서는 응력지수값이 저 응력구간에서 대략 6 7을 나타내다가, 고 응력구간에서는 응력지수값이 약 4 로 감소하였다. 고 응력범위에서 응력지수값이 감소하는 현상은 $\mathrm{Zr}-\mathrm{Sn}-\mathrm{Fe}-\mathrm{Cr}$ 및 $\mathrm{Zr}-\mathrm{Nb}-\mathrm{Sn}-\mathrm{Fe}$ 합금에 포함되어 있는 용질원자 $\mathrm{Sn}$ 의 확산과 전위의 상호작용에 따른 동적변형시효 현상에 기 인한 것으로 판단된다. $\mathrm{Sn}$ 의 함량이 많은 $\mathrm{Zr}-\mathrm{Sn}-\mathrm{Fe}-\mathrm{Cr}$ 합금에서 응력지수값의 변화가 더 급격하게 감소한 것은 $\mathrm{Sn}$ 함량이 많을수록 전위에 작용하는 drag force의 크기가 증가하여 응력지수값을 더 많이 낮춘다는 Hong의 동적 변형시효 모델의 예측결과와 일치한다.

4) 본 연구에서는 활성화 에너지 값이 응력이 증가함에 따라 Zircaloy-4의 경우에는 $240 \mathrm{~kJ} / \mathrm{mol}$ 에서 $270 \mathrm{~kJ} / \mathrm{mol}$ 로, $\mathrm{Zr}-\mathrm{Nb}-\mathrm{Sn}-\mathrm{Fe}$ 합금의 경우에는 $240 \mathrm{~kJ} / \mathrm{mol}$ 에서 $260 \mathrm{~kJ} /$ mol로 증가하였다.

5) 두 합금 모두 저 응력 구간에서는 칼날전위 climb에 의한 creep 기구가 creep 율속기구이지만 고 응력 구간에 서는 전위-합금원소 상호작용에 의한 칼날전위의 점성활 주가 creep 율속기구에 기여하고 있는 것으로 판단된다. 동적변형시효 효과는 $\mathrm{Sn}$ 의 함량이 많은 $\mathrm{Zr}-\mathrm{Sn}-\mathrm{Fe}-\mathrm{Cr}$ 합금 의 경우 고 응력구간에서 더 큰 $\mathrm{drag}$ force가 작용하여 $\mathrm{Zr}-\mathrm{Nb}-\mathrm{Sn}-\mathrm{Fe}$ 합금에 비해 응력지수값을 더 감소시키고 활 성화 에너지를 더 증가시키는 것으로 보인다.

6) $\mathrm{Zr}-\mathrm{Sn}-\mathrm{Fe}-\mathrm{Cr}$ 및 $\mathrm{Zr}-\mathrm{Nb}-\mathrm{Sn}-\mathrm{Fe}$ 합금에 대한 creep 파단 유형을 관찰한 결과, 두 합금 모두 비슷한 유형의 파단이 진행되고 있는 것으로 관측되었으며, 온도 및 응력 이 증가할수록 파단유형이 입내파괴에서 입계파괴로 천 이됨을 확인하였다.

\section{감사의 글}

본 연구는 지식경제부 지원 원자력연료(주) 위탁과제로 수행되었으며, 지원에 감사드립니다.

\section{참 고 문 헌}

1. E. Kohn, Zirconium in the Nuclear Industry, ASTM STP 633, 402 (1977).

2. K. W. Lee, S. K. Kim, K. T. Kim, S. I. Hong, J. Nucl. Mater., 295, 21 (2001).

3. O. S. Ivanov and U. K. Grigorovitch, Second International Conference on Peaceful Uses of Atomic energy, Genova, 5, 34 (1958)

4. W. A. Mcinteer, David L. Baty and K. O. Stein, Zirconium in the Nuclear Industry, ASTM STP, 1023, 621 (1989).

5. B. Cox and C. E. Lundin, Proceedings of the USAEC Syposium on Zirconium Alloy Development, p.9 Castlaewood, Pleasanton, Califonia, (1962).

6. D. G. Franklin, G. E. Lucas, A. L. Bement, Creep of Zirconium Alloy in Nuclear Reactors, p.183, ASTM, (1993).

7. K. Linga Murty, J. Ravi, Wiratmo, Nuclear Enginerring and Design., 156, 359 (1995).

8. J. Weertman, Trans, AIME, 218, 207 (1960).

9. J. D. Lubahn, R. P. Felgar, Plasticity and Creep of Metals, p.210, wiley, (1961).

10. K. L. Murty, G. S. Clevinger, T. P. Papazogloa, Trans, of the 4th Int. Conf. on Structural Mechanics in Reactor Technology, p.C3/4, Vol C, SF, CA, (1977).

11. S. I. Hong: Mater. Sci. Eng., 86, 211 (1987).

12. S. I. Hong: Mater. Sci. Eng., 64, L19 (1984).

13. S. I. Hong: Mater. Sci. Eng., 91, 137 (1987).

14. S. I. Hong: Mater. Sci. Eng., 82, 175 (1986).

15. S. I. Hong: Mater. Sci. Eng., 79, 1 (1986).

16. H. Oikawa, K. Honda and S. Ito, Mater. Sci. Eng., 64, 237 (1984).

17. Y. Zhoy, B. Devarajan, K. L. Murty, Nuclear Enginerring and Design., 228, 3 (2004).

18. J. Y. Park, H. G. Kim, Y. H. Jeong, Y. H. Jung, J. Nucl. Mater., 335, 433 (2004).

19. G. P Sabol, G. R. Kilp, M. G. Balfour and E. Roberts, Zirconium in the Nuclear Industry, ASTM STP, 1023, 227 (1989).

20. D. O. Northwood, X, Meng and B. O. Warr, ASTM STP, 1132, 156 (1991). 